\title{
FERTILIZER REQUIREMENTS IN HAWKE'S BAY, WAIRARAPA AND MANAWATU
}

\author{
C. During and A. J. McNeur
}

Soil and Field Research, M inistry of Agriculture and Fisheries, $\mathrm{H}$ amilton and $\mathrm{H}$ astings

\section{INTRODUCTION}

'THE phosphate cycle under grazing and the practical significance of phosphate fixation are briefly discussed, as are maintenance requirements of fertilizers, effects on pasture production when fertilizers are not used for one or two years, and finally, liming.

\section{THE PHOSPHATE CYCLE UNDER GRAZING}

Under sheep grazing, an appreciable amount of phosphate is removed from the major part of the paddock in the form of dung and added to tracks and stock camps. Accurate information on the quantities of phosphate involved in this migration oh phosphate within a paddock was collected by Gillingham and During (1973) on a hilly paddock near Hamilton grazed by sheep, and some of the results obtained are illustrated in Fig. 1. If it is assumed that pasture on a given area of a hill country paddock takes up 100 units of phosphorus in a year, it is likely that two-thirds of the area in pasture produced 56 units of phosphate but only 41 units were returned to that area in dung and dead herbage. Thus, on a hectare of hill slope producing about $40 \mathrm{~kg}$ phosphorus/ha/ $\mathrm{yr}$, some $10 \mathrm{~kg}$ might be transferred or lost. On the other hand, there was a definite accumulation of phosphate on $6 \%$ of the paddock and a situation of near balance on $25 \%$. This work did not take into account some of the uneven distribution that occurs between tracks and intertrack areas on steep land. Tracks may occupy $25 \%$ or more of a steep hillside (During and Radcliffe, 1962). There will be other losses of phosphate that have not been adequately measured, for instance by erosion of surface soil and by downward movement under cattle dung (Weeda, 1976). In many cases loss of phosphorus from the main grazing area is appreciable, and is possibly equivalent to 80 to $120 \mathrm{~kg}$ superphosphate/ha/yr on intensively grazed sheep farms, and slightly more on dairy farms. 

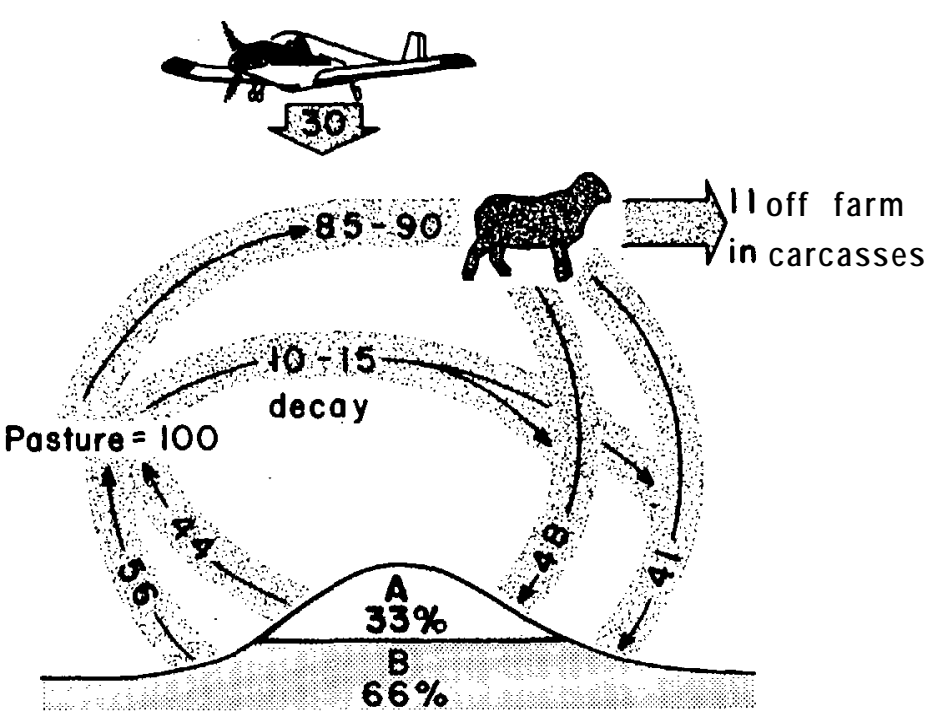

FIG. 1: Phosphorus cycle on a hill country paddock grazed by sheep. (Gillingham and During, 2973.)

A: Includes stock camps and areas where $P$ removal and return is in balance $(33 \%$ of total area).

B: Remainder of paddock experiencing loss of $\mathrm{P}$.

PHOSPHATE RETENTION OR SORPTION BY SOILS

Phosphate retentioa, or more correctly "phosphate sorption", is measured in a laboratory test (Saunders, 1965). Soils are shaken with a solution containing a standard amount of phosphate and the phosphate removed from the solution by the soil is measured; the more phosphate removed the stronger the retention properties of that particular soil. Many people use the term fixation, which implies. that the phosphate removed from solution is fixed, and is no longer available to plants but this is quite wrong.

As with other soil analyses, phosphate retention' tests must be' calibrated against field trials. Work carried out so far suggests that phosphate retention values are positively correlated with maintenance requirements of phosphate but that the importance of phosphate retention tends to be overstated by some sections of the agricultural industry.

\section{SULPHATE RETENTION}

In field experiments on the West Coast of the South Island, white clover developed sulphur deficiency a few months after it 
had been topdressed with large quantities of sulphate. This was the result of two factors, high rainfall and the inability of the soil to retain sulphate against leaching. A sulphate retention test was developed (During and Martin, 1968) to predict the ability of the soil to retain sulphate. It is thus obvious that high sulphate retention is a 'beneficial characteristic, while high phosphate retention is not. Most soils in the southern half of the North Island have low sulphate retention, but because the rainfall is not particularly high there is no rapid development of sulphur deficiency. Thus in trials on Matapiro soils in Hawke's Bay with very low sulphate retention, virtually no yield responses to sulphur topdressing were obtained on pasture over a number of years (W. M. H. Saunders, pers. csmm.) .

\section{MAINTENANCE REQUIREMENTS OF SOILS FOR PHOSPHATE}

In their native state, most soils are phosphate-deficient and initially require relatively large quantities of this element to grow and maintain good pasture. If these requirements are met and heavy rates are applied, rates much in excess of what is carried off or transferred by the grazing animal, phosphorus accumulates in the top few inches of soil. In consequence, phosphate fertility gradually rises and maintenance requirements gradually fall. It is perhaps not sufficiently appreciated that this position has been reached on very many farms. Phosphate fertility is high owing to past topdressing and the quantity of phosphate that needs to be applied can be reduced considerably from previous levels.

The question now arises how to assess the level of this newly acquired soil fertility and how to adjust topdressing rates to it. The Ministry of Agriculture and Fisheries obtains this knowledge from rates of phosphate trials, the results of which are related to various phosphate soil tests. Taken by themselves, soil tests, particularly in the medium range 04 values, are not very accurate indicators of phosphate fertility, but together with a knowledge of past topdressing history they have proved valuable. From now onwards discussion will be confined to farms that have been topdressed regularly, namely for some ten years or more with 150 to $400 \mathrm{~kg}$ superphosphate/ha/yr, and that have Truog soil test levels of 5 to 15 .

As already indicated, phosphate requirements are influenced by phosphate retention, because this characteristic seems to be correlated with losses of phosphate in the soil. 'Requircments are also affected by rainfall, partly because it influences pasture production and therefore stocking rates, and partly because it has 
been found that phosphate fixation in the soil increases with moisture (Barrow, 1974) . Soils, therefore, are divided into three main groups according to rainfall and phosphate retention as shown in Fig. 2. Group 1 comprises the yellow-grey earths, with a mean annual rainfall of 750 to $1000 \mathrm{~mm}$, and a $\mathrm{P}$ retention of 10 to 60 . Group 2 comprises yellow-brown earths, pumice soils and coastal sands. The mean annual rainfall is $1000 \mathrm{~mm}$ or more and .P retention 20 to 85 . Group 3 includes the yellow-brown loams derived mainly from volcanic ash, with a mean annual rainfall of. $1000 \mathrm{~mm}$ or more, and a $\mathrm{P}$ retention of 85 and over.

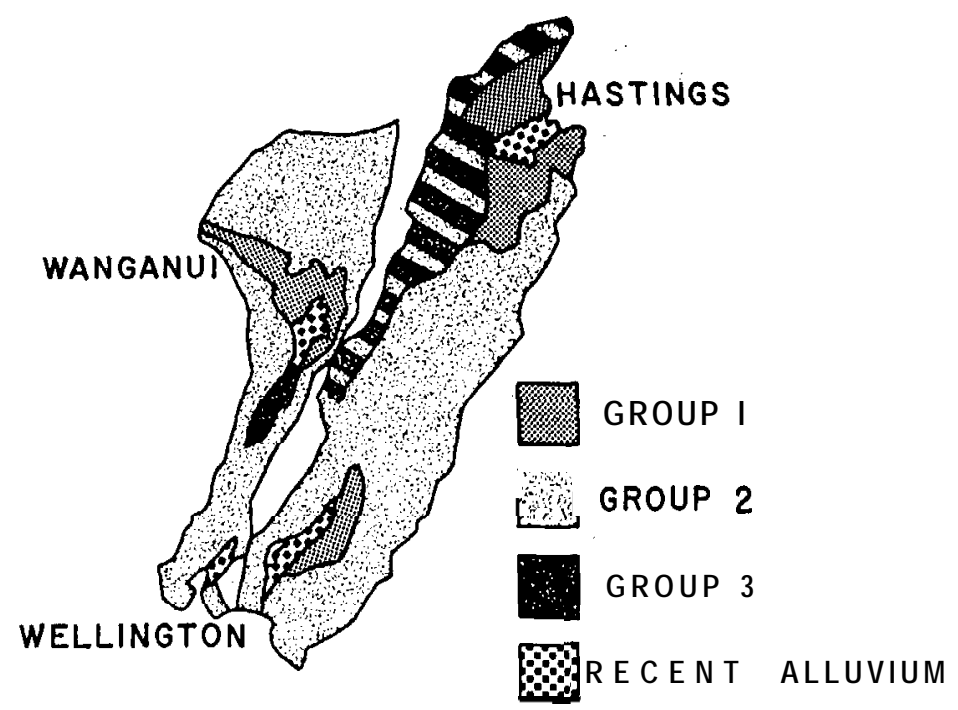

FIG. 2: Outline of three soil groups.

1. Low $\mathrm{P}$ retention;-mean annual rainfall $<1000 \mathrm{~mm}$.

2. Low or medium $P$ retention, rainfall $>1000 \mathrm{~mm}$.

3 . High $\mathrm{P}$ retention, rainfall $\geqslant 1000 \mathrm{~mm}$.

The scale used in Fig. 2, however, does not allow great accuracy. In particular, much of the drier hill country in Hawke's Bay and Wairarapa should be shown in Group 1 instead of Group 2, and Group 3 soils cover relatively small area's in noncontiguous patterns; this is shown by hatching. The best means of differentiating between Group 2 and Group 3 soils is by the P retention test.

Present knowledge -on maintenance requirements comes from local rate of phosphate trials such as one near Takapau, from experiments near Masterton (Bircham and Crouchley, 1976), 
FERTILIZER REQUIREMENTS

TABLE 1: ESTIMATE OF ANNUAL PHOSPHATE REQUIREMENTS, TRUOG P TEST 5-12, REGULARLY TOPDRESSED FOR 10-15 YEARS

\begin{tabular}{|c|c|c|c|c|}
\hline Soils & $\begin{array}{l}\text { uperphosphafe } \\
(\mathrm{kg} / \mathrm{ha} / \mathrm{yr})\end{array}$ & $\begin{array}{c}\text { Pasture DM } \\
\text { Rel. to Maximum } \\
=100\end{array}$ & $E E / h a$ & $\begin{array}{c}\text { Tonnes } \\
\text { Superphosphate } \\
\text { per } 1000 \mathrm{EE}\end{array}$ \\
\hline \multicolumn{5}{|l|}{ Group 1: } \\
\hline Arable & 125 & 85 & $12-15$ & $8-10$ \\
\hline Arable & 250 & 95 & $13-16$ & $16-20$ \\
\hline Hilly, dry & 125 & 7 & $8-12$ & $10-15$ \\
\hline \multicolumn{5}{|c|}{ Group 2: } \\
\hline Arable & 180 & 85 & $12-17$ & $10-15$ \\
\hline Arable & 300 & 95 & $12-18$ & $17-25$ \\
\hline Hilly & 180 & $?$ & $10-12$ & $15-18$ \\
\hline steep & 180 & $?$ & 10 & 18 \\
\hline \multicolumn{5}{|l|}{ Group 3: } \\
\hline Arable & 250 & 85 & $12-16$ & $16-20$ \\
\hline Dry & 500 & 93-95 & $12-17$ & $30-40$ \\
\hline
\end{tabular}

Marton, Wellington and also from Nelson (M. B. O'Connor perș. comm.) where Group 2 soils are very similar to some found in the North Island. These results are summarized and interpreted in Table 1.

On sheep farms it is doubtful whether maintenance at levels higher than $85 \%$ of maximum is economic in most years. So, if that level is taken as the guide, and if it is accepted that losses of phosphate from the main grazing area are somewhere near the equivalent of $80 \mathrm{~kg}$ superphosphate/ha/yr, the conclusion is reached that phosphate is reasonably efficiently utilized under grazing, unless of course near-maximum production is the aim. If this is done, the phosphate status of New Zealand soils is gradually increasing. If this increase results in an improvement of the phosphate status below the first few inches of soil, it may well be beneficial in districts experiencing summer droughts.

Table 1 suggests that, on light, friable, highly phosphateretentive soils with an annual rainfall of $1000 \mathrm{~mm}, 250 \mathrm{~kg}$ superphosphate can maintain pasture production at about $85 \%$ of its maximum. Slightly higher levels of topdressing for this level of relative production may be required in the high rainfall1 districts near the ranges (Karlovsky, 1973). There is virtually no informiation on maintenance requirements of phosphatic fertilizer on hillsides, because it is extraordinarily difficult to measure true pasture production under grazing on hilly land. It can be seen, 
however, that many farmers should be able to carry 1000 ewe equivalents with an annual input of 1.0 to 15 tonnes of superphosphate, oc, in Ad-fashioned language, $1 \mathrm{cwt}$ of superphosphate should maintain 3.3 to 5 ewe equivalents.

\section{MAINTENANCE REQUIREMENTS FOR POTASH AND SULPHUR}

Both sulphur and potash are removed from the main grazing area by the same transfer mechanism as phosphorus, because animals distribute their excreta unevenly and wool and meat sold off the farm contain both sulphur and potash. Sulphur can also be iost by leaching if the retentive capacity of soils for sulphate is low and the rainfall high enough. Leaching is very much more likely to be important on light friable soil on gravel beds than on deep silt or clay loams. Blackmore et al. (1969) reported quite acute sulphur deficiencies in a series of trials on unimproved, untopdressed sites, but many other trials carried out on developed farms before and since have indicated that, except on some pumice soils, pasture production is not affected if topdressing is omitted for several years.

Superphosphate does not supply potash, so when superphosphate only is used the potassium status of soils must fall, and in 'fact potassium deficiency is widespread. It is best identified by soil test (critical level about 4) and by visual signs of deficiency in pastures. Trial evidence suggests that in most cases $100 \mathrm{~kg}$ potassium chloride will maintain 85 to $90 \%$ of maximum production. However, to correct severe deficiencies higher rates are needed in the first year.

\section{THE EFFECT ON PASTURE PRODUCTION OF OMITTING \\ PHOSPHATIC TOPDRESSING}

This subject was discussed recently (During and O'Connor, 1975) and Table 2 summarizes the position as it applies to local districts, and it can be seen that in most soils the drop in production will be small.

The percentage decline in pasture production in late autumnwinter can be much larger than the percentage of annual decline. This can greatly affect the feed position on heavily stocked farms at a critical time of the year, winter and early spring. For this reason outright cmission of topdressing is not advisable on Group 3 soils, but a temporary reduction in the rate of topdressing may do little harm. 
TABLE 2: DECLINE IN PASTURE PRODUCTION IN THE YEAR FOLLOWING OMISSION OF ANNUAL PHOSPHATE TOPDRESSING IN PADDOCKS WITH TRUOG P TEST 5.12, REGULARLY TOPDRESSED 10-15 YEARS

\begin{tabular}{cc}
\hline Soils & $\begin{array}{c}\text { First } \\
\text { in }\end{array}$ \\
$\begin{array}{c}\text { Year's Decline } \\
\text { Production } \\
(\%)\end{array}$ \\
\hline Group 1: \\
Arable \\
Hilly \\
Group 2: \\
Arable & $0-9$ \\
Hilly & very small \\
Group 3: & $0-9$ \\
Arable & $0-5$ \\
\hline
\end{tabular}

\section{OMISSION OF SULPHUR AND POTASSIUM TOPDRESSING}

In Grcaps 1 and 3 the omission of sulphur topdressing for one or more years is not likely to affect pasture production. In Group 2 there is some experimental evidence, though not complete, that soils derived from Taupo ash may require sulphur for pasture production at Fairly regular intervals, even after they have been developed for many years.

Slightly excessive rates of application of potash tend to lead to a useful accumulation- of this element in the soil, but it is not always possible to estimate the magnitude of such accumulations with sufficient accuracy. Generally speaking, potassic topdressing should best be kept as an annual event.

\section{THE VALUE OF LIME}

Recently research effort into the meaning of soil pH has greatly increased, and a large number of field trials with rates of lime are under way at present. Many of these need to continue for a few more years before results can be reported. However, it seems that on the Matapiro soils, a prominent series in Hawke's Bay, relatively low $\mathrm{pH}$, from 5.0 to 5.4 , is compatible with high pasture and animal production, and yield responses to liming have not been obtained in experiments. On the other hand near Masterton, on the Kokotau soil with $\mathrm{pH}$ 5.4, Bircham and Crouchley (1976) obtained a 20\% yield response to liming. At Marton, During and Rolt (1967) found that maximum production was achieved at about pH 6.0. Work in other districts, notably Nelssn Province (M. B. O'Connor, pers. comm.) has revealed similar 
inconsistencies between soil $\mathrm{pH}$ and lime responses. New soil tests are being developed (During and Brier, 1973) that may predict lime responses more accurately than $\mathrm{pH}$, and there is a considerable amount of work going on in the laboratory at Ruakura. In particular we are looking at aluminium, an element that becomes soluble with increasing acidity and is known to be toxic to plants and some micro-organisms. Manganese is also under investigation (W. M. H. Saunders, pers. comm.) .

We cannot accept the claim that liming improves stock thrift irrespective of what it does to pasture yields. Careful measuremenis at Masterton (J. S. Bircham and G. Crouchley, pers. comm.) working with sheep have not shown an improvement in any measurable characteristic and in an experiment at Stratford, N. A. Thomsoa (pers. comm.) has found a higher incidence of hypomagnesaemia of dairy cows on limed than on unlimed pasture.

Neither does lime necessarily improve the utilization of phosphate, although this has been observed in New Zealand (During et al., 1960). On the other hand, Larsen et al. (1965) in England found that the higher the soil $\mathrm{pH}$ the lower the residual value of phosphate applied in the past - that is, liming immobilized soil phosphate and made it less available to plants. This effect seems to operate at levels above $\mathrm{pH} 6$.

\section{CONCLUSIONS}

After years under grazing and topdressing, phosphate and sulphur accumulate in soils and the general soil fertility, other than in potassium and magnesium, rises. This applies to the majority of farmed soils and these are the ones under discussion.

(1) Many farmers have not adjusted their topdressing practices to this change in fertility. Too much phosphate is applied, extra sulphur is used where it is not needed, and potassium deficiency may often be neglected to the detriment of the overall financial position of the farm.

(2) It has been found that the omission of phosphatic and sulphur topdressing for one year, and often for a longer period, has little effect on pasture production. This applies particularly on soils where mean annual rainfall does not exceed about $1000 \mathrm{~mm}$.

(3) In the long run, however, losses of phosphate, sulphur, and potassium from the main grazing area must be made good. and the scale of these losses is not so greatly different from 
the amounts of topdressing tht have been found to maintadn quite high pasture production.

(4) Claims that a very large proportion of the cycled or applied phosphate is irretrievably fixed are greatly exaggerated, if not downright wrong.

(5) The place of lime on southern North Island soil's is being studied quite intensively both in the field and the laboratory. Lack of a good soil test to predict the need for lime is oae of the main problems; the other is that pasture responses to lime tend to vary so much with season.

\section{ACKNOWLEDGEMENTS}

Assistance from the staff at the Takapau Field Research Area and from the science technicians at Hastings is gratefully acknowledged. Illustratioas were doae by Miss P. Hunt.

\section{REFERENCES}

Barrow, N. J., 1974. Soil Science, 118: 380-6.

Bircham, I. S.; Crouchley, G., 1976. N.Z. Il exp. Agric., 4: in press.

Blackmore, L. W.; Ludecke, T. E.; Hogg, E., 1969. Proc. N.Z. Grassld Ass., 31: 87-95.

During, C.; Brier, G. J., 1973. N.Z. /l agric. Res., 16: 9-11

During, C.; Martin, D. J., 1968. Ibid., 11: 665-76.

During, C.; Lynch, P. B.; McNaught, K. J.; Scott, R. S., 1960. Ibid., 3: 950-93.

During, C.; O'Connor, M. B., 1975. Proc, Ruakura Fmrs' Week, 27: 30-4. During, C.; Radcliffe, J., 1962. Trans. int. Soil Conf. Comm. IV and V: 685-7.

During, C.; Rolt, W. F., 1967. N.Z. agric. Sci., I: 17-22.

Gillingham, A. G.; During, C., 1973. N.Z. Il exp. Agric., 1: 227-32

Karlovsky, J., 1973. Proc. N.Z. Grassld Ass., 35: 22-9.

Larsen, S.; Gunary, D.; Sutton, C. D., 1965. J. Soil Sci., 16: 141-S.

Saunders, W. M. H., 1965. N.Z. Il agric. Res., 8: 30-57.

Weeda, W. C., 1976. Ibid.: in' press. 